\title{
Initial and Mid-Term Outcomes of Pulse Infusion Thrombolysis Using a Unique Pump System and Stent Placement for Deep Vein Thrombosis
}

\author{
Seiji Hokimoto ${ }^{1}$, Taro Saito ${ }^{2}$, Shuichi Oshima ${ }^{3}$ and Hisao Ogawa ${ }^{4}$
}

\begin{abstract}
Objective The aim of this study was to evaluate the initial and mid-term results of pulse infusion thrombolysis (PIT) using a unique pump system and stent placement for proximal deep vein thrombosis (DVT) in Japanese.

Methods Among the patients who were admitted to our institute under diagnosis of proximal DVT between April 2001 and March 2005, 11 patients (4 men, mean age 61 years) who underwent PIT and angioplasty followed by stent placement were enrolled in this retrospective analysis. Urokinase or monteplase was used as a thrombolytic agent. Venous or stent patency was assessed by color Doppler ultrasound or enhanced computed tomography for a mean follow-up duration of 54 months.

Results Sites of thrombus were left lower limbs in 10 cases and left upper limb in one case. Initial technical (complete venous flow recovery) and clinical (disappearance of pain and swelling of diseased leg or arm) success was achieved in all patients. Two of 11 patients showed stent occlusion with leg swelling and pain one month later and 3 years later, respectively. These patients had associated protein S deficiency.

Conclusion PIT and stent deployment for DVT is safe and effective with favorable initial and mid-term clinical results and without major complications in Japanese, except for cases of congenital coagulation abnormality.
\end{abstract}

Key words: deep vein thromobosis, thrombolysis, stent

(Inter Med 47: 1663-1667, 2008)

(DOI: 10.2169/internalmedicine.47.1024)

\section{Introduction}

Deep vein thrombosis (DVT) is a commonly observed disorder which sometimes triggers serious complications. It has been reported that thrombolytic therapy for iliofemoral DVT may be superior to anticoagulation therapy, and that catheter-directed thrombolysis might potentially provide improved initial and long-term results compared to a systemic infusion of thrombolytics (1-4). Previously, we have reported the safety and efficacy of pulse infusion thrombolysis using a unique pump system (PIT) for thrombotic diseases such as acute myocardial infarction with huge intracoronary thrombus, vein graft occlusion after coronary artery bypass graft surgery, and DVT $(5,6)$. Although the safety and efficacy of catheter-directed thrombolysis and stent placement for DVT has been demonstrated, the long-term results, especially in Japanese, remain unknown (7-9). We report cases of PIT and stent deployment for DVT and demonstrate the early and late outcomes in Japanese.

\section{Methods}

\section{Subjects}

Among the patients who were admitted to our institute

\footnotetext{
${ }^{1}$ Department of Interventional Cardiology, Division of Coronary Intensive Care Unit, Kumamoto University Hospital, Kumamoto, ${ }^{2}$ Heart Center, Fukuoka Wajiro Hospital, Fukuoka, ${ }^{3}$ Division of Cardiology, Kumamoto Central Hospital, Kumamoto and ${ }^{4}$ Department of Cardiovascular Medicine, Graduate School of Medical Sciences, Kumamoto University, Kumamoto

Received for publication February 17, 2008; Accepted for publication June 23, 2008

Correspondence to Dr. Seiji Hokimoto, seisan@momo.so-net.ne.jp
} 
Table 1. Clinical and Procedural Characteristics

\begin{tabular}{|c|c|c|c|c|c|c|c|}
\hline Pt No & $\operatorname{Age}(y) / \operatorname{Sex}$ & $\begin{array}{l}\text { Location of } \\
\text { Thrombus }\end{array}$ & $\begin{array}{l}\text { Thrombolytics } \\
(\times 10,000 U)\end{array}$ & $\begin{array}{l}\text { Duration from } \\
\text { onset (days) }\end{array}$ & $\begin{array}{l}\text { Associated } \\
\text { diseases }\end{array}$ & $\begin{array}{l}\text { Follow-up } \\
\text { (months) }\end{array}$ & $\begin{array}{l}\text { Follow-up } \\
\text { stent patency }\end{array}$ \\
\hline 1 & $77 / \mathrm{F}$ & CIV-SFV(left) & UK96 & 15 & Disk herniation & 75 & no problem \\
\hline 2 & $49 / F$ & CIV-Pop(left) & Mo160 & 38 & Fracture of femur & 68 & no problem \\
\hline 3 & $65 / M$ & CIV-Pop(left) & Mo80 & 20 & Depression & 67 & no problem \\
\hline 4 & $63 / F$ & CIV-SFV(left) & Mo160 & 30 & Obesity & 65 & no problem \\
\hline 5 & $35 / F$ & CIV-Pop(left) & Mo160 & 14 & Protein S deficiency & 64 & occlusion \\
\hline 6 & $50 / \mathrm{F}$ & CIV-Pop(left) & Mo80 & 17 & Fracture of leg & 55 & no problem \\
\hline 7 & $55 / M$ & EIV-SFV(left) & Mo80 & 29 & Hematoma post cath & 79 & no problem \\
\hline 8 & $53 / M$ & Subclavia(left) & Mo80 & 14 & Colon cancer & 48 & no problem \\
\hline 9 & $83 / M$ & CIV-SFV(left) & Mo80 & 30 & Inguinal hernia & 37 & no problem \\
\hline 10 & $77 / F$ & CIV-Pop(left) & Mo80 & 23 & Protein S deficiency & 36 & occlusion \\
\hline 11 & $67 / F$ & CIV-SFV(left) & Mo80 & 22 & Anthropathy in knee & 30 & no problem \\
\hline
\end{tabular}

under diagnosis of DVT between April 2001 and March 2005, although 11 patients had already taken anticoagulation therapy in our or another hospital, they were suffering leg pain and swelling, thus the patients who underwent PIT and venoplasty followed by stent placement were enrolled in this retrospective analysis (Table 1). There were 4 men and 7 women. The mean age was 61.3 years (range, 35-83 years). Follow-up lasted 30-75 months (mean, 54.0 months). The study protocol was in agreement with the guidelines of the ethical committee of the institution and written informed consent was obtained from each patient or the family of the subject.

\section{PIT and angioplasty procedure}

PIT pump (Nemoto Kyorindo, Tokyo, Japan) allows constant forceful delivery of fibrinolytic agent in a spray-like fashion through multiple side holes of PIT catheter directly in the thrombus (Fig. 1). This pump system may also have an advantage that a prolonged procedure is possible. The detailed system was described as before and as a PIT catheter; the Cragg-McNamara catheter [Micro Therapeutics, Inc., Irvine, CA, USA] as used (6).

Temporary inferior vena caval filter [Neuhaus Laboratories, Inc., Miami, FL, USA] was placed in the proximal IVC before PIT to inhibit pulmonary thromboembolism. A bolus of heparin $(5,000$ units) was given through the venous line. After the 0.035 inch guidewire crossed the thrombus lesion via the femoral or cervical vein, the PIT catheter was passed into the thrombosed occlusion site. PIT $(960,000$ units of urokinase or $800,000-1,600,000$ units of tissue plasminogen activator; monteplase/200 $\mathrm{mL}$ of saline) was performed step by step at each site every 5 to 10 minutes, as reported in our previous study (6). Resolving thrombi after PIT were easily removed with use of an aspiration thrombectomy catheter, if necessary, using a coronary guiding catheter (8 French Judkins R type) as a thrombectomy catheter. After PIT and suction thrombectomy, when venography showed persistent stenosis, the lesion was treated by balloon dilatation. However, if there was a still underlying stenosis in the proximal vein, which diameter was more than $8 \mathrm{~mm}$, PALMAZ (Johnson \& Johnson company, Miami, FL), Wall (Boston Scientific Corporation, Natick, MA), or LUMINEXX (BARD, Murray Hill, New Jersey) stent was delivered. Deployed stents were expanded with use of an angioplasty balloon of appropriate diameter.

After the procedure, patients underwent anticoagulation therapy with heparin initially, followed by orally administered warfarin.

\section{Definitions and follow-up}

Initial technical success was defined as the complete restoration of continuous flow. Clinical success was defined as disappearance of pain and swelling edema of diseased limbs. Early complications were defined as procedure-related complications. There were acute or subacute stent thrombosis, and thrombolysis-related complications such as bleeding and hematoma. The major complications were bleeding or hematoma necessitating transfusion, and death. Late complications were defined as the recurrence of symptoms, such as pain and swelling edema of diseased limbs. Pulmonary thromboembolism was defined when thrombotic occlusion of the pulmonary artery was detected by computed tomography.

Patients were followed by hospital visits or telephone interview, and stent patency was assessed by color Doppler ultrasound or enhanced computed tomography at 1, 6 and 12 months, and then yearly thereafter.

\section{Results}

As shown in Table 1, the number of cases was 11 (4 men), and mean age was 61 years old ( 35 to 83 years). Culprit sites of thrombosis were left lower limbs in 10 cases, and left subclavian vein in one case. As a thrombolytic 


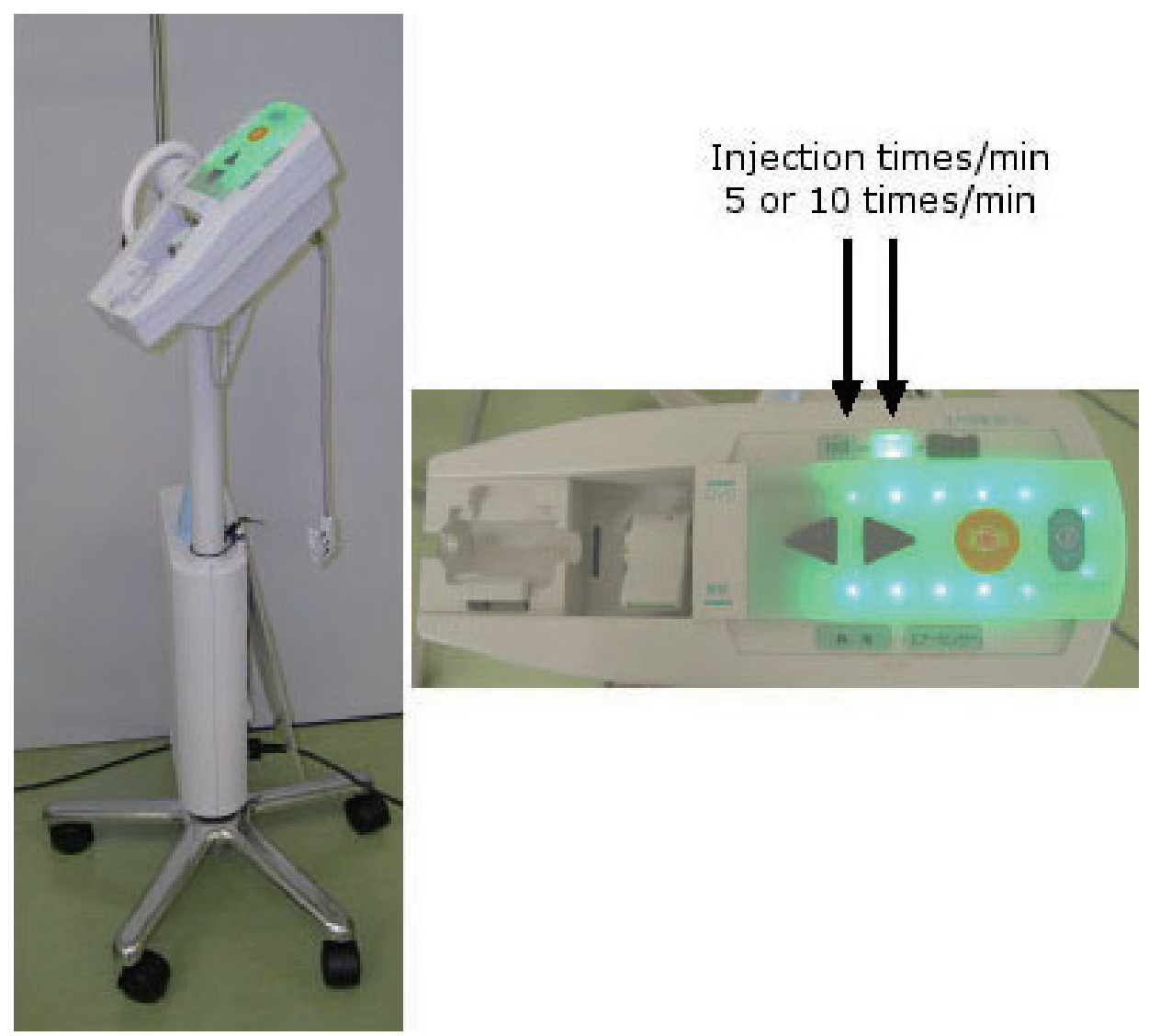

Figure 1. Pump system. Delivery of the thrombolytic agent can be [changed 5 or 10 times/min] to fit the thrombus age, size and stability. The volume per one bolus is $0.5 \mathrm{~mL}$.

Table 2. Stent Deployment

$\begin{array}{llllll}\text { Pt No } & \text { Age }(y) / \text { Sex } & \text { Stent site } & \text { Type } & \text { No of stent } & \text { Venousfollow up } \\ 1 & 77 / F & \text { left CIV } & \text { PALMAZ } & 1 & \text { patent } \\ 2 & 49 / F & \text { left CIV } & \text { PALMAZ } & 1 & \text { patent } \\ 3 & 65 / M & \text { left CIV } & \text { PALMAZ } & 1 & \text { patent } \\ 4 & 63 / F & \text { left CIV } & \text { PALMAZ } & 2 & \text { patent } \\ 5 & 35 / F & \text { left CIV } & \text { PALMAZ } & 1 & \text { occlusion } \\ 6 & 50 / F & \text { left CIV } & \text { PALMAZ } & 1 & \text { patent } \\ 7 & 55 / M & \text { left CFV } & \text { Wall } & 1 & \text { patent } \\ 8 & 53 / M & \text { left Subcl } & \text { PALMAZ } & 1 & \text { patent } \\ 9 & 83 / M & \text { left CIV } & \text { PALMAZ } & 1 & \text { patent } \\ 10 & 77 / F & \text { left CIV } & \text { LUMINEXX } & 2 & \text { occlusion } \\ 11 & 67 / F & \text { left CIV } & \text { PALMAZ } & 1 & \text { patent }\end{array}$

CIV; common iliac vein, CFV; common femoral vein, Subclavia; subclavian vein

agent, urokinase was used in 1 patient at a dose of 960,000 $\mathrm{U}$, and monteplase in 10 subjects with $800,000-1,600,000 \mathrm{U}$ (Table 1). A patient (No 7 in Table 1) had a cardiac catheter implaced via the left femoral vein 1 month previously. Another patient (No 8 in Table 1) with subclavian vein stenosis was associated with the frequent venous puncture for intravenous hyperalimentation following an operation for colon cancer. As noted in Table 2, in terms of stent types, Palmaz stents were used in 9 cases and a Wall stent and Luminexx stent in one case each. Stents were deployed in just lesions proximal to the left common iliac veins in 9 cases, of which the lesions were iliac compression syndrome and left common femoral vein in 1 case, which was associated with phlebitis and hematoma following puncture of the femoral vein and artery, and left subclavian vein in one case, which was associated with inflammation after frequent needle 

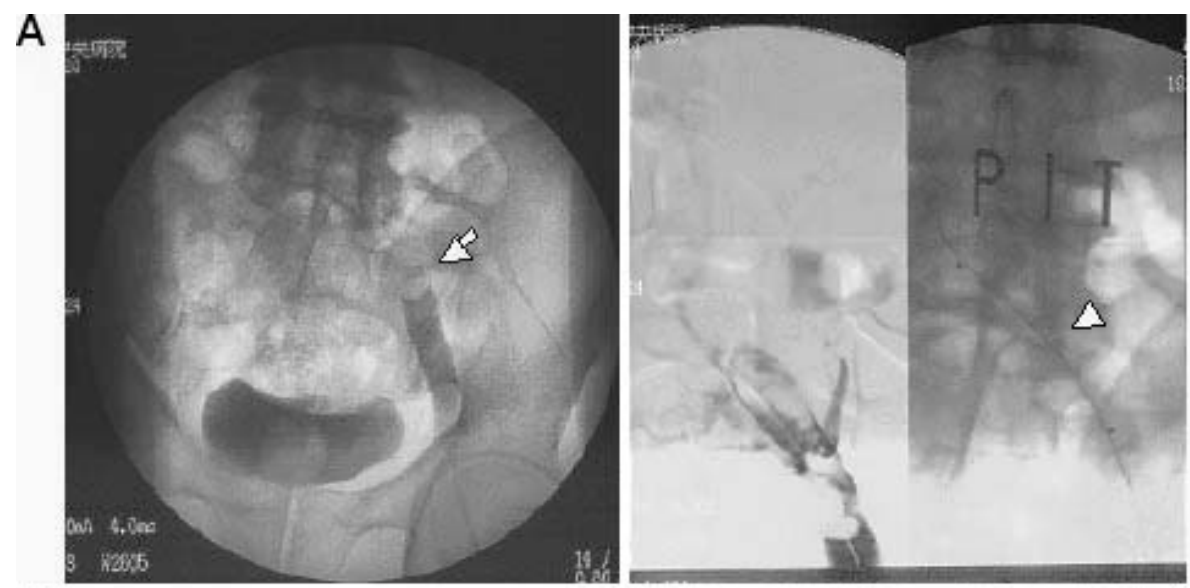

\section{C}
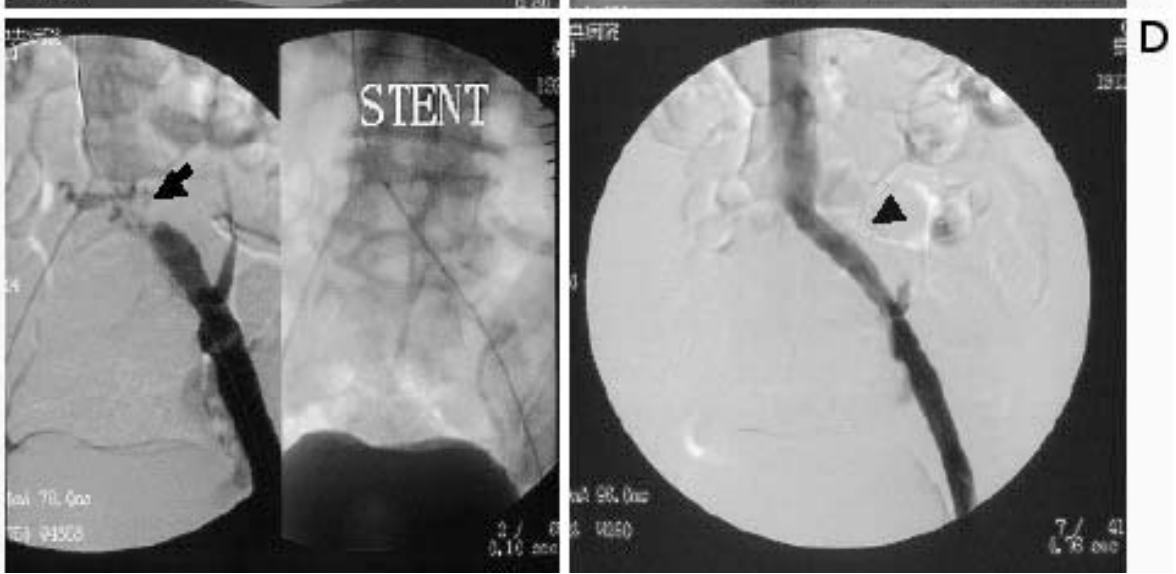

Figure 2. Pulse infusion thrombolysis and stent placement. The case is an 83-year-old man with a painful, swollen left leg due to extensive DVT diagnosed by computed tomography. A: Venography showed huge thrombus formation in the iliac and femoral veins, with occlusion of the common iliac vein (white arrow). B: PIT was performed with tissue plasminogen activator, monteplase as a thrombolytic agent through the Cragg-McNamara infusion catheter (white arrowhead). C: Venography after PIT demonstrated the stenosis of common iliac vein (black arrow), and stent deployment was performed, D: Venography after Palmaz 9×42 mm stent deployment and expansion to $10 \mathrm{~mm}$ diameter with an angioplasty balloon showed a widely patent common iliac vein (black arrowhead).

puncture. The mechanism of venous stenosis was thought to be associated with postphlebitic adhesion after puncture in these 2 patients. Initial technical and clinical success was achieved in all patients.

Neither perioperative death nor pulmonary embolism occurred. There were no major adverse effects and no early complications.

A typical DVT case treated with PIT and stent is shown in Fig. 2.

Two of the 11 patients showed stent occlusion at one month and 3 years after PIT and stent procedure, respectively. The remaining 9 cases showed primary venous patency and symptom resolution for a mean follow-up duration of 54 months. There was no pulmonary embolism during the follow-up period.

\section{Discussion}

Traditional therapy for proximal DVT has been systemic heparin followed by oral warfarin. The results of this antico- agulant therapy have been generally inadequate in terms of resolution of symptoms and recanalization of long-segment venous occlusions $(1,8)$. Systemically administered thrombolytic agents are associated with a high incidence of partial thrombolysis, residual venous stenosis, and a significant rate of bleeding complications (2). Thrombolytic therapy has been reported to be more effective than anticoagulation therapy for massive or limb threatening DVT, and methods of delivery of thrombolytic agents include systemic infusion, local-regional administration, and catheter-directed therapy (10). PIT is one of the catheter-directed thrombolysis therapies and lyses thrombi by the synergetic mechanisms of mechanical maceration by direct spray-like delivery of thrombolytic solution into the thrombus using a unique pump system. Fibrinolytic acceleration by PIT was confirmed experimentally $(11,12)$. We previously reported the case of PIT alone treated without stent placement for proximal DVT (6). In this study, we showed the initial and mid-term results of PIT and stent deployment for DVT.

Catheter-directed thrombolysis for DVT requires a lengthy 
procedural time and large amount of thrombolytic agent. Mewissen et al demonstrated the efficacy of catheterdirected thrombolysis for DVT, and that the mean dose of urokinase and procedural time were 7.8 million $U$ and 53 hours, respectively (3). Moreover, the average urokinase dose and procedural time in another previous report by Kwak et al were 1,980,000 U and 14 hours, respectively (8). In this study, the procedural time was about 5 hours and within the usual quantity of thrombolytic agent; the amount of thrombolytic as well as the procedural time was reduced compared to those of previous reports. Moreover, although 11 patients in this study had already taken anticoagulation therapy in our or another hospital, they were suffering from leg pain and swelling, thus the duration from onset to PIT and stent was long, nevertheless, PIT using a unique pump system might facilitate the restoration of venous flow and the reduction of amount of thrombolytic agent or procedural time. The usual dosage of thrombolytics might reduce the incidence of bleeding complications.

It has been reported that primary iliofemoral venous patency rates at 1 and 3 years were $83 \%$ and $69 \%$ in DVT patients treated by lysis/stent placement (13). Moreover, another previous study demonstrated that stent patency in the left common iliac vein was good for a mean follow-up duration of 21 months, and that the 2-year primary patency rate was $95 \%$ (8). In this study, 2 of 11 patients showed stent occlusion at one month and 3 years later, respectively. Protein $\mathrm{S}$ activity was $16 \%$, and $24 \%$ in these 2 subjects, thus it seems that stent deployment for venous stenosis should be refrained from patients with congenital blood coagulation disorder, especially protein $\mathrm{S}$ deficiency.

In our institution, invasive therapy including PIT has been performed for 18 patients with DVT, who suffered from pain and swelling edema of the leg. The cases were PIT+ Stent deployment in 11, PIT alone in 2, PIT+balloon dilatation (BA) in 5 patients. In PIT alone and PIT+BA groups, although one patient died of prostatic cancer 3 years after the PIT, venous flow was restored in the residual cases. Basically, if necessary, stents were delivered in just proximal lesions of left common iliac veins due to iliac compression syndrome, or post-phlebitic venous stenotic lesions due to frequent needle puncture. Thus, the data from PIT+stent group can not be compared with the data from PIT+BA or PIT alone group.

\section{Conclusion}

PIT and stent placement for proximal DVT showed good results of stent patency without recurrence of symptoms in Japanese for a mean follow-up duration of 54 months, except for the patients with protein $\mathrm{S}$ deficiency. Moreover, PIT using a unique pump system might allow for the treatment with reduced dosage of thrombolytic agent, in a shorter procedural time, and without major bleeding complications.

\section{Acknowledgement}

The authors are grateful to Kayoko Okazaki for assistance with collecting the data.

\section{References}

1. Strandness DE, Langlois $Y$, Cramer M, Randlett A, Thiele BL. Long-term sequelae of acute venous thrombosis. JAMA 250: 1289-1292, 1983.

2. Semba CP, Duke MD. Catheter-directed thrombolysis for iliofemoral venous thrombosis. Semin Vasc Surg 8: 405-418, 1996.

3. Meissner MH. Thrombolytic therapy for acute deep vein thrombosis and the venous registry. Rev Cardiovasc Med 3: S53-S60, 2002.

4. Mewissen MW, Seabrook GR, Meissner MH, Cynamon J, Labropoulos N, Haughton SH. Catheter-directed thrombolysis for lower extremity deep venous thrombosis: Report of a national multicenter registry. Radiology 211: 39-49, 1999.

5. Saito T, Hokimoto S, Ishibashi F, Noda K, Oshima S. Pulse infusion thrombolysis (PIT) for large intracoronary thrombus: preventive effect against the 'no flow' phenomenon in revascularization therapy for acute myocardial infarction. Circ J 65: 94-98, 2001.

6. Hokimoto S, Saito T, Noda K, et al. Challenging case of pulse infusion thrombolysis using a unique pump system for a patient with deep vein thrombosis: A case report. J Cardiol 39: 115-119, 2002.

7. Patel NH, Stookey KR, Ketcham DB, Cragg AH. Endovascular management of acute extensive iliofemoral deep venous thrombosis caused by May-Thurner syndrome. J Vasc Interv Radiol 11: 1297-1302, 2000.
8. Kwak HS, Han YM, Lee YS, Jin GY, Chung GH. Stent in common iliac vein obstruction with acute ipsilateral deep venous thrombolysis: early and late results. J Vasc Interv Radiol 16: 815822, 2005 (Erratum in: J Vasc Interv Radiol 16: 1120, 2005).

9. Yamada N, Ishikura K, Ota S, et al. Pulse-spray pharmacomechanical thrombolysis for proximal deep vein thrombosis. Eur $\mathrm{J}$ Vasc Endovasc Surg 31: 204-211, 2006.

10. Alesh I, Kayali F, Stein PD. Catheter-directed thrombolysis (intrathrombus injection) in treatment of deep venous thrombosis: A systemic review. Catheter Cardiovasc Interv 70: 143-148, 2007.

11. Bookstein JJ, Saldinger E. Accelerated thrombolysis: In vitro evaluation of agents and methods of administration. Invest Radiol 20: 731-735, 1985.

12. Kandarpa K, Drinker PA, Singer SJ, Caramore D. Forceful pulsatile local infusion of enzyme accelerates thrombolysis: In vivo evaluation of a new delivery system. Radiology 168: 739-744, 1988.

13. AbuRahma AF, Perkins SE, Wulu JT, Ng HK. Iliofemoral deep vein thrombosis: Conventional therapy versus lysis and percutaneous transluminal angioplasty and stenting. Ann Surg 233: 752$760,2001$.

(C) 2008 The Japanese Society of Internal Medicine http://www.naika.or.jp/imindex.html 